\title{
On the Indexing of Anthropological Journals
}

\begin{abstract}
Literature searching in anthropology and archaeology illustrates the complexity of relationships and title dispersion characteristic of the social science literatures. There are, however, current indexes which often provide a basic list of references, which appropriate national and other bibliographies may strongly supplement.
\end{abstract}

D IANA AMsDen's article, “Information Problems of Anthropologists,"1 indicates very clearly the difficulties experienced by research workers in this discipline; Irene Taeuber's classic essay on the information problems in demography ${ }^{2}$ was concerned with just the same sort of difficulty: the complexity of the relationships between the various social sciences, the variety of physical forms in which information appears, the importance of the geographical orientation of so much of the literature, the immense title dispersion which results from these factors, and so on.

However, this brief note is to suggest that the situation is not quite as desperate as the one Miss Amsden describes, though it is certainly quite desperate enough.

If one considers indexing over the whole field of anthropology and archae-

\footnotetext{
IDiana Amsden, "Information Problems of Anthropologists," CRL, XXIX (March 1968), 117-31.

2 Irene B. Taeuber, "The Social Sciences; Characteristics of the Literature, Problems of Use, and Bibliographic Organization in the Field," in Jesse $H$. Shera \& Margaret E. Egan, eds., Bibliographic Organization (Chicago: University of Chicago Press, 1951), pp. 127-39.
}

Mr. Routh is Reference Librarian and Mrs. McPherson is Reference Assistant in the University of Queensland, Brisbane. ology, there can be no doubt that there is a great variety of abstracts and indexes which index some periodicals of interest to workers in the field, but it can be argued that it would be very seldom that those named in Miss Amsden's "Analysis of Indexing" would be used early in a literature search in either anthropology or archaeology. A more natural starting point for references to periodical articles in many searches would be the Index to Current Periodicals Received in the Library of the Royal Anthropological Institute, and (after eliminating duplication) at least 103 of the periodicals in the Anthropology and Archaeology sections of Ulrich 1966 are included among the periodicals analyzed in that index. The International Bibliography of Social and Cultural Anthropology provides an alternative approach (except, of course, in such fields as physical anthropology): its lists of periodicals for 1964 and 1965 include at least 86 of the Ulrich titles. After duplications are eliminated the two indexes cover 123 of the Ulrich periodicals, being decidedly stronger for anthropology than for archaeology (as one might expect). Compare this with the thirty-nine periodicals cited by Miss Amsden ( $p$. 120). 
Further, the many deficiencies of the two aforementioned current bibliographies may be powerfully remedied in some fields of anthropological research by appropriate specialist or regional reference sources, such as Annual Bibliography of Indian Archaeology, Australian Public Affairs Information Service, Dansk Tidsskrift-Index, and so on. Admittedly such sources (especially national periodical indexes) may not be available in a specialist library, but in a large general reference library it is often simple for the research worker whose enquiry has a geographical limitation to use one or two indexes of this kind, with considerable profit.

Finally, however, one has to admit that many anthropologists are working in fields where they can have little confidence that they have found a really substantial percentage of the references that would be useful to them. Until, probably, the development of a really comprehensive bibliographical service allowing a great variety of approaches, the scholar working in the Australian field is unlikely to discover that one working with a South American tribe has made an advance in some field technique that would be of benefit to him: it is the Weinberg Report's ${ }^{3}$ problem of "switching" again, and the situation is indeed desperate.

\footnotetext{
${ }^{3}$ U.S. President's Science Advisory Committee, Science, Government, and Information (Washington,
} 